\title{
ISTO E AQUILO: O JOGO DAS HISTÓRIAS EM A CASA DA CABEÇA DE CAVALO, DE TEOLINDA GERSÃO
}

Orivaldo Rocha da Silva ${ }^{1}$

RESUMO: Este artigo tem como objetivo analisar aspectos de construção narrativa no romance $A$ Casa da Cabeça de Cavalo, de Teolinda Gersão, focando principalmente os expedientes de contar e recontar histórias ou os de apresentar as muitas versões possíveis para um mesmo acontecimento, constituindo o que podemos denominar como o jogo das histórias, a estratégia narrativa básica utilizada no romance.

PALAVRAS-CHAVE: Histórias; Jogo das histórias; Teolinda Gersão.

ABSTRACT: This article aims to analyze some aspects of narrative construction in the novel A Casa da Cabeça de Cavalo, by Teolinda Gersão, focusing mainly the strategies of telling and retelling stories or to introduce the many possible versions for an event, establishing what we can denominate like stories game, the basic narrative strategy used in this novel.

KEYWO RDS: Stories; Stories game; Teolinda Gersão.

"Ou se tem chuva e não se tem sol / ou se tem sol e não se
tem chuva!
[... É uma grande pena que não se possa / estar ao mesmo
tempo nos dois lugares!
[... Ou isto ou aquilo: ou isto ou aquilo... / e vivo
escolhendo o dia inteiro!
[... Mas não consegui entender ainda / qual é melhor: se
isto ou aquilo."
(Cecília Meirelles, Obra Poética).

A questão da crise da linguagem é como que uma marca dos universos narrativos de Teolinda Gersão em seus dois primeiros romances. Aspectos de experimentação linguística que já se faziam presentes em O Silêncio (1981) e Paisagem com mulher e mar ao fundo (1982) serão potencializados em Os guarda-chuvas cintilantes (1984), obra identificada pela autora como "Diário" na própria folha de rosto, mas que em verdade não permite ao leitor classificála tão facilmente assim, por conta de sua complexa heterogeneidade. A liberdade da escrita presente nos Guarda-chuvas aproxima a obra da estética surrealista justamente quando são observados aspectos de certo experimentalismo elevado aos mais altos níveis. É este o traço a distinguir Os guarda-chuvas cintilantes como escrita sui generis no conjunto da produção de Teolinda.

\footnotetext{
1 Mestrando em Letras pelo Programa de Pós-Graduação em Literatura Portuguesa da Faculdade de Filosofia, Letras e Ciên cias Humanas (FFLCH) da Universidad e de São Paulo (USP).
} 
A respeito de O Cavalo de Sol (1989), romance que também obteve reconhecimento da crítica por meio da concessão do Prêmio de Ficção do Pen Clube, o que já se dera com a obra de estreia da autora, é possível observar uma preocupação por imprimir à sua estrutura uma menor fragmentação e, consequentemente, uma mais acentuada linearidade em comparação ao que se tem nas três obras anteriores. Quase esquematicamente, o romance divide-se em quatro partes, que se prestam a ditar os diferentes ritmos da leitura a partir dos movimentos do cavalo: 1. Passo; 2. Trote; 3. Galope; 4. Salto. De modo geral, sua temática está em sintonia com a dos primeiros romances, qual seja, a das relações conflituosas entre homem e mulher, do opressor e do oprimido. No entanto, é pertinente também pensar numa leitura de O Cavalo de Sol que aponte para uma libertação do "Sistema" (elemento opressor) justamente quando se considera o seu último segmento.

Importa ainda destacar que foi no romance de 1989 que as primeiras referências à Casa da Cabeģa de Cavalo, objeto deste estudo, apareceram. A trama envolvendo Vitória e Jerônimo tem lugar no espaço da casa, desde já com toda sua ancestralidade reconhecida:

Porque não precisavam dela, eles, os da Casa da Cabeça de Cavalo, com pergaminhos antigos, vindos de Dona Balbina Teresa, filha de Dom Francisco Inácio e de Dona Genebra Joaquina, [...] que tinha no frontão um escudo dividido em pala e meio unicórnio como timbre. (GERSÃO, 1995, p.28-29).

Pois esse mesmo espaço - de presença até certo ponto secundária em O Cavalo de Sol-será retomado no romance $A$ Casa da Cabeça de Cavalo (1995) e promovido a espaço de fundamental importância para a sorte da narrativa. Além do espaço da casa, é também recuperada a figura do cavalo, porém, em chave distinta. Nos termos de Lilian Jacoto,

é curioso, entretanto, o significado singular que o cavalo assume neste romance [A Casa da Cabeşa de Cavalo], se comparado aos demais, de mesma autoria, em que ele aparece. Essencialmente tomado como símbolo das pulsões eróticas em Teolinda Gersão, o cavalo aqui está associado à morte. (JACOTO, 2009, p. 106).

Passemos agora a explorar um pouco mais A Casa da Cabeça de Cavalo, quinta incursão de Teolinda Gersão ao romance (sem considerar sua produção de literatura infantil História do homem na gaiola e do pássaro encarnado, de 1982). Também reconhecida pela crítica, a obra recebeu o Grande Prêmio de Romance e Novela da Associação Portuguesa de Escritores. 
Casa e cavalo são apresentados ao leitor "como descrição objetiva e vivência simbólica" (JACOTO, 2009, p. 104) perceptíveis já desde os primeiros capítulos e mesmo pelo inusitado de seu título. De certo modo, é possível considerar que o romance recupera alguns dos temas já tratados por Teolinda em obras anteriores, embora seja nele marcante um maior desenvolvimento de aspectos ligados à História ou, mais especificamente, de uma particular concepção de História.

A diferença mais expressiva entre a Casa e os romances anteriores de Teolinda reside num momento anterior ao do mergulho no conteúdo da obra: a leitura de seu índice apresenta uma divisão em 24 capítulos, devidamente titulados. Tal estrutura não é encontrada em qualquer outro romance anterior da autora. Apenas em O Cavalo de Sol é que as suas quatro partes são identificadas, assim mesmo não se prestando a revelar maior detalhamento. $\mathrm{O}$ que se tem nos dois primeiros romances é uma divisão por blocos numerados e, em Os guardachuvas cintilantes, como é próprio do gênero "diário", os fragmentos são encimados apenas pelo dia da semana e do mês. Sem maiores aprofundamentos, é viável então pensar para a obra uma estrutura narrativa seriada e que guarda semelhanças, por exemplo, com o gênero dos romances de folhetim. Dessa forma, as inúmeras histórias que pululam na Casa encontram arcabouço dos mais adequados, já que são inúmeros também os cruzamentos, as interpolações e as retomadas. Bastaria a leitura dos títulos dos capítulos 6 e 7 para ilustrar os movimentos internos que acabamos de apontar. "6 - Chegada Inesperada de Um Francês"; "7 - Onde se Repete, Para a Ver Melhor, a Chegada do Francês”. As múltiplas vozes dos habitantes invisíveis da casa servem-se da memória para manter acesa a chama das histórias e é "no cruzamento do tempo e da memória" (DIOGO, 1998, p. 351) que se dá "a possibilidade de guardar na memória e contar a(s) história(s) da existência das coisas e das pessoas [e] que permite implantar marcos no tempo. Deste modo, a memória torna-se, é narrativa." (DIOGO, 1998, p. 351). A questão da memória - e, por extensão, a da lembrança, a da reminiscência e a do esquecimento - dos jogos de memória, diríamos, deve também ser objeto de análise no romance, já que os aspectos ligados ao jogo, ao lúdico, ao puzzle são recorrentes no texto de Teolinda.

O concerto de múltiplas vozes que se presta, aparentemente, a conceber as narrativas encaixadas no romance desdobra-se naturalmente numa multiplicidade de pontos de vista, traço onipresente na Casa desde os seus primeiros parágrafos. O próprio narrador, com o 
intuito de não permitir que a matéria narrada resvale para o caos do incompreensível absoluto através de um trabalho de organização e seleção dos discursos, por vezes hesita e quase se deixa tragar na vertigem das narrativas. Vejamos como se dá a descrição da casa, a começar por sua voz:

A Casa tinha cabeça de cavalo. Ou se quisermos, mais prosaicamente: tinha uma cabeça de cavalo na parede. [...] Durante a manhã, o sol percorria a cabeça, subindo pelas crinas. Ao meio dia tocava no dorso e ao poente começava a bater-lhe na garupa, descendo lentamente pelas patas. O dorso, a garupa e as patas não eram visíveis, como se tivessem sido devorados pela Casa. Mas é verdade que todo o corpo do cavalo existia. (GERSÃO, 1995, p. 13).

Logo adiante, a multiplicidade de versões será exposta pelo narrador de modo flagrante, quando os aspectos físicos e mesmo psicológicos do cavalo passam a ser elencados livremente e sem que prevaleça um ponto de vista sobre outro:

Havia quem dissesse que o cavalo era de bronze. Mas alguns juravam que em várias ocasiões tinham visto o seu pêlo luzir, macio e húmido, e quando the tocavam tinham sentido debaixo da mão o latejar das veias, o sangue vivo correndo debaixo do pêlo castanho. (GERSÃO, 1995, p. 14).

Era, segundo outros, um cavalo muito jovem, inseguro, que experimentava com volúpia as suas patas flexíveis, [...] Porque ele era, [...] um cavalo sem idade, que em cada primavera renascia. (GERSÃO, 1995, p. 14-15).

Outros ainda juravam que o cavalo era negro e louco. (GERSÃO, 1995, p. 15).

Por fim, é ainda o próprio narrador quem, à guisa de conclusão, busca apresentar ao leitor um possível ordenamento para o caos narrativo que já se configurava:

Diremos, se não entenderam nada do que se disse atrás e pedirem explicações mais concretas, que o nome lhe vem portanto de uma muito real cabeça de cavalo, de bronze escuro, cravada na parede de pedra, junto à porta de entrada. (GERSÃO, 1995, p. 14-15).

Ocorre que estamos diante da ruptura de um dos princípios da chamada lógica formal (ocidental) ou "[d]a lógica binária que se estrutura a partir da alternativa: ou isto ou aquilo [...]" (ALVES, 2003, p. 268). Na Casa de Teolinda, as várias versões para um mesmo fato são acolhidas e nenhuma delas é descartada por se tratar de uma meia verdade, embora 
ninguém “ousava imaginar o que viam” (GERSÃO, 1995, p. 15) os olhos enormes do cavalo, sua presumida visão totalizante das coisas e que se coloca de forma inacessível à visão parcial dos olhos do homem:

assim dispostos um de cada banda da cabeça, cada um olhando um lado das coisas, e a visão de ambos somando talvez uma verdade inteira. Diferentemente dos olhos humanos, que viam apenas em frente, e se obstinavam em não ter mais do que uma visão unilateral do universo. (GERSÃO, 1995, p. 15).

O contar e o recontar das histórias, as muitas versões possíveis de um mesmo acontecimento, a multiplicidade de opiniões, em outros termos, o jogo das histórias, constitui então estratégia narrativa básica no romance e, a partir do Capítulo 3 - "Alguns Habitantes Invisíveis", passam a ser sumariamente apresentadas e a ter espaço na trama toda uma legião de vozes do passado já extintas, figuras invisíveis que podem ser reintroduzidas na ordem das coisas, readquirindo visibilidade justamente por força das inúmeras narrativas encaixadas, das narrativas de memória que saltam das páginas do romance.

Apoiando-se em Todorov e sua discussão acerca da narrativa e das narrativas encaixadas, Maria Heloísa Martins Dias afirma que o ato de "inscrever histórias dentro de um circuito narrativo ininterrupto é, de certo modo, retomar uma tradição" (DIAS, 1992, p. 151) e, nesse ponto, o modelo considerado exemplar é o das narrativas que compõem As Mil e Uma Noites:

Se todos os personagens contam histórias ininterruptamente, é porque este ato recebeu uma consagração suprema: contar é igual a viver. O exemplo mais evidente é o da própria Xehrazade que vive unicamente na medida em que pode continuar a contar; [...] A narrativa é igual à vida; a ausência de narrativa, à morte. Se Xehrazade não encontrasse mais histórias para contar, seria executada. (TODOROV, 1979, p. 88-89).

Também os habitantes invisíveis da casa só adquirem presença novamente por conta das narrativas de memória que passam a ser construídas, como num jogo, por cada um deles, ao retomar o que era contado e recontar, ou mesmo ao interromper a qualquer momento o que era narrado e prosseguir, sem a preocupação de se ater a uma verdade: o importante era não deixar que a memória se apagasse e que as histórias deixassem de ser 
contadas. Utilizemos como exemplificação desse processo o conteúdo do capítulo 14 do romance, "Memórias de Carlota".

Carlota é uma das figuras femininas da casa - além de Umbelina, Maria do Lado, Virita, Eugênia e Maria Badala - irmã do patriarca Duarte Augusto e que se envolverá com Gaudêncio, afilhado do padre e a respeito de quem, como é recorrente no romance, não se tem absoluta certeza de quase nada. Dessa forma, alguns também diziam (“as más línguas”) que ele não era afilhado, e sim filho do padre; para muitos outros, como para a própria Carlota, o homem era uma espécie de palhaço, um artista, um saltimbanco; outros também diziam que o seu talento maior era o de transformar as coisas, atribuindo-lhe então, habilidades de prestidigitador. O fato é que Gaudêncio partirá para Pernambuco e deixará Carlota a bordar, sempre à sua espera. Nesse ponto, é importante lembrar que todas as figuras e fatos acima destacados são originários das narrativas de memória construídas pelos habitantes invisíveis da casa e, como pano de fundo "oficial”, a alusão ao episódio da fuga da família real portuguesa é realizada igualmente por meio de mais de uma versão. A fuga se deu para salvação do trono português ou por medo da invasão francesa?

No capítulo em análise, temos então uma das "pequenas histórias" ou uma "história privada" entrelaçando-se com a chamada "grande História" ou "História pública (oficial)" e promovendo sua reinterpretação. Mais do que a História, a "pequena história" de Carlota presta-se também a ilustrar o processo de retomada (em novas bases) do mito de Penélope. Ocorre que, já desde as linhas iniciais, é possível antever que algo de sombrio subverterá o mito, nessa retomada, realizando também a sua releitura.

O lençol bordado de Carlota, disse Ercília. Os pontos de cruz, miúdos, em fileiras muito juntas, todos os fios contados. Os olhos ardendo. A luz e a sombra misturadas, a chama torta da vela, pingos de cera caindo do castiçal [...] O medo no corpo, disse Carmo. (GERSÃO, 1995, p.129).

E, sobretudo no segmento abaixo descrito, todo o caráter sombrio e de subversão do mito se mostrará mais claramente quando o discurso de Ercilia (habitante invisível que "conduz" a história no momento) se entrelaça ao da própria Carlota para introduzir, como narrativas encaixadas, a temática ligada ao universo dos feitiços, das bruxas e das bruxarias: 
e diziam e diziam e ela bordava e bordava e continuava a contar os fios, mesmo depois de a Casa se fechar e não se saber se era noite ou dia, disse Ercilia. Bordava e espetava os dedos, uma agulha em cada dedo e cinco na palma da mão, sobre as linhas da vida, e o sangue corria nos sulcos do destino e manchava o lençol e ela tocava no sangue com a língua e pensava em Gaudêncio, e armava um feitiço com o sangue, a vela e a cruz, ninguém vai dar conta de que a cruz se esconde no bordado, ninguém vai descobrir o feitiço, pontos da cruz da minha sina, Gaudêncio meu Cristo e minha cruz. (GERSÃO, 1995, p. 130).

O concerto de múltiplas vozes, dissociadas assim de um narrador e geradas por habitantes invisíveis que "não tem mais uma existência objetiva [...] e constituem [...], portanto, [...] uma essência puramente literária” (JACOTO, 2009, p. 105), permite lembrar que a linguagem literária já não se fixa nem mesmo a um sujeito, e na medida em que "se coloca sempre fora de si mesma, [...]" (LEVY, 2003, p. 29) substitui "a intimidade do sujeito pelo Fora da linguagem [...]” (LEVY, 2003, p. 29). Em linha com tal conceituação (originária de Blanchot e comentada por Levy), Roberto Machado (referindo-se a Michel Foucault) explicita que "a linguagem nem remete a um sujeito nem a um objeto: elide sujeito e objeto, substituindo o homem [...] por um espaço vazio fundamental onde ela se propaga, se expande, se repetindo, se reduplicando indefinidamente" (MACHADO, 2000, p. 113). Ou, em outros termos, a linguagem literária é a exterioridade por excelência e, em verdade, não é falada por ninguém (MACHADO, 2000, p. 115). Nesse ponto, parece também pertinente lembrar que autores da estatura de Maurice Blanchot, Michel Foucault e Roland Barthes, dentre outros, apontaram o caráter pioneiro de Mallarmé no sentido de posicionar a linguagem em primeiro plano ou "a necessidade de colocar a própria linguagem no lugar daquele que era até então considerado seu proprietário; para ele, como para nós, é a linguagem que fala, não o autor" (BARTHES, 2004, p. 59). E com Blanchot, autor fundamental para a discussão dos aspectos ligados ao fora e à linguagem literária, é importante ainda destacar que "a fala poética deixa de ser fala de uma pessoa: nela, ninguém fala e o que fala não é ninguém, mas parece que somente a fala 'se fala'. A linguagem assume então toda a sua importância; torna-se o essencial" (BLANCHOT, 2011, p. 35).

A linguagem é também o essencial para a manutenção da existência dos antepassados da Casa, já que configura a permanência da memória, garante o fluir ininterrupto das narrativas e preserva o jogo das histórias. Extinta a memória, não há mais narrativas e se 
avizinha o fim, aproxima-se o nada. Ou o espaço vazio e silencioso da origem da própria linguagem:

Olharam uns para os outros e empalideceram e eram como pedaços de vela sumindo, restos de memória que acabava. [...] um resto de memória que se ia gastando, como uma vela de cera, e quando acabasse também eles chegariam ao fim e não haveria mais nada. (GERSÃO, 1995, p. 246-247).

As palavras que agora não são mais expressas reproduzem-se no escuro, inaudíveis, e não permitem mais divisar sequer um ponto de referência. Extinta a memória, extintas as narrativas, desaparecida a Casa da Cabeça de Cavalo, resta apenas um "espaço imenso e vazio" (GERSÃO, 1995, p.248), no qual os habitantes invisíveis apenas se procuram uns aos outros, com medo de perder-se.

\section{Referências}

ALVES, Maria Theresa Abelha. "A Casa da Cabeça de Cavalo: A morte como lucidez". Scripta, Belo Horizonte, v. 6, n. 12, p. 266-281, 1. Sem. 2003.

BARTHES, Roland. "A morte do autor". In: O Rumor da lingua. Trad. Mario Laranjeira. São Paulo: Martins Fontes, 2004, p. 57-64.

BENJAMIN, Walter. “O narrador - Considerações sobre a obra de Nikolai Leskov". In: Magia e técnica, arte e política. Trad. Sérgio Paulo Rouanet. São Paulo: Editora Brasiliense, 1994, p. 197221.

BLANCHOT, Maurice. O espaço literário. Trad. Álvaro Cabral. Rio de Janeiro: Rocco, 2011. - A parte do fogo. Trad. Ana Maria Scherer. Rio de Janeiro: Rocco, 1997.

BRITO, Casimiro de. "Teolinda Gersão: Os guarda-chuvas cintilantes". Colóquio/Letras, Lisboa, n. 89, p. 93-95, jan/1986.

DIAS, Maria Heloísa Martins. O pacto primordial entre mulher e escrita na obra ficcional de Teolinda Gersão. 268f. Tese (Doutorado em Letras - Literatura Portuguesa) - Faculdade de Filosofia, Letras e Ciências Humanas, Universidade de São Paulo, São Paulo, 1992.

DIOGO, Ana Teresa. "Teolinda Gersão: A Casa da Cabeça de Cavalo". Colóquio/Letras, Lisboa, n. 147-148, p. 351-352, jan/1998.

FOUCAULT, Michel. "Linguagem e Literatura”. In: MACHADO, Roberto. Foucault, a filosofia e a literatura. Rio de Janeiro: Jorge Zahar Editor, 2000, p. 138-174. 
- O que é um autor? Trad. António Fernando Cascais e Eduardo Cordeiro. Lisboa: Passagens, 2009.

- A linguagem ao infinito. In: Estética: Literatura e Pintura, Música e Cinema. (Coleção Ditos e Escritos III). Trad. Inês Autran Dourado Barbosa. Rio de Janeiro: Forense Universitária, 2006, p. 47-59.

O pensamento do exterior. In: Estética: Literatura e Pintura, Música e Cinema. (Coleção

Ditos e Escritos III). Trad. Inês Autran Dourado Barbosa. Rio de Janeiro: Forense Universitária, 2006, p. 219-242.

GERSÃO, Teolinda. Os guarda-chuvas cintilantes. Lisboa: O Jornal, 1984.

. O cavalo de sol. Lisboa: Publicações Dom Quixote, 1989.

- A Casa da Cabeça de Cavalo. Lisboa: Publicações Dom Quixote, 1995.

. O silêncio. 4. ed. Lisboa: Publicações Dom Quixote, 1995.

. Paisagem com mulher e mar ao fundo. 4. ed. Lisboa: Publicações Dom Quixote, 1996.

GOMES, Álvaro Cardoso. A voz itinerante. São Paulo: Editora da Universidade de São Paulo, 1993.

JACOTO, Lilian. "A pena da galhofa de Teolinda Gersão: A Casa da Cabeça de Cavalo". In: FERNANDES, Annie Gisele; SILVEIRA, Francisco Maciel (orgs.). A Literatura portuguesa: visões e revisões. São Paulo: Ateliê Editorial, 2009, p. 103-116.

KONG-DUMAS, Catherine. "Teolinda Gersão: Paisagem com mulher e mar ao fundo". Colóquio/Letras, Lisboa, n. 73, p. 78-80, mai/1983.

LEVY, Tatiana Salem. A experiência do fora: Blanchot, Foucault e Deleuze. Rio de Janeiro: Relume Dumará, 2003.

LOURENÇO, Eduardo. "Literatura e Revolução". Colóquio/Letras, Lisboa, n. 78, p. 7-16, $\operatorname{mar} / 1984$.

MACHADO, Roberto. Foucault, a filosofia e a literatura. Rio de Janeiro: Jorge Zahar Editor, 2000.

MARTINHO, J.B. "Os habitantes invisíveis da casa”. In: SILVEIRA, Jorge Fernandes da (org.). Escrever a casa portuguesa. Belo Horizonte: Editora UFMG, 1999, p. 213-217.

MEIRELLES, Cecília. Obra Poética. Rio de Janeiro: Nova Aguilar, 1987.

OLIVEIRA, Cristina Cordeiro. “Teolinda Gersão: O Silêncio”. Colóquio/Letras, Lisboa, n. 65, p. $81-83$, jan/1982. 
SEIXO, Maria Alzira. "Dez anos de literatura portuguesa (1974-1984): ficção". Colóquio/Letras, Lisboa, n. 78, p. 30-42, mar/1984.

SILVEIRA, Jorge Fernandes da. "Casas de Escrita". In: SILVEIRA, Jorge Fernandes da (org.). Escrever a casa portuguesa. Belo Horizonte: Editora UFMG, 1999, p. 13-21.

TODOROV, Tzvetan. "Os homens-narrativa”. In: Poética da Prosa. Trad. Maria de Santa Cruz. Lisboa: Edições 70, 1979, p. 81-94.

ZAMBONIM, Maria Thereza Martinho. O silêncio em Teolinda Gersão. 197f. Tese (Doutorado em Letras - Literatura Portuguesa) - Faculdade de Filosofia, Letras e Ciências Humanas, Universidade de São Paulo, São Paulo, 1997.

Artigo recebido em 27de Março de 2012 e aprovado em 14 de Maio de 2012 